\title{
The terminal HVDC model and DC voltage slope control strategy based on MMC
}

\author{
Si-Si Shi , Xin-Yan Zhang ${ }^{\dagger}$, Bo-Wen Liu and Guan-Qi Zhang, \\ School of Electrical Engineering, Xinjiang University, \\ Urumqi, 830047, China \\ $\dagger$ E-mail:465667381sss@sina.com
}

\begin{abstract}
In order to study the MTDC model and control strategy based on modular multilevel converter, Firstly, according to the working principle of MMC, The mathematical model in the DQ coordinate system of the multi-terminal direct current based on voltage source converter is deduced. Secondly, according to the DQ decoupling control theory, the converter station controller is designed based on MMC. Finally, design a control strategy of the DC voltage slope compensate for the defects that only one converter as the DC voltage control station.

Keywords: Modular multilevel converter; MTDC; DC voltage slope; control strategy.
\end{abstract}

\section{Introduction}

HVDC based on Voltage Source Converter (VSC-HVDC) was first proposed by Boon-Teck Ooi of Canadian McGill University in 1990[1,2]. Its main characteristic is the voltage source converter which is composed of the full control power electronic device is used to replace the current source converter which is composed of semi controlled thyristor devices. Because this technology has good controllability and flexibility, it has been highly concerned by many researchers in the world. The test project (Hellsjon Project) which is based voltage source converter HVDC for the first time running and successed in 1997 by the ABB. The project promotes the development of engineering application of voltage source converter based on HVDC technology[3].

With the development of high power electronic switching devices, the cost of direct current transmission is gradually reduced, the research of the new control strategy and the improvement of power quality, the VSC-HVDC technology has been developed rapidly. It is greatly improves the practicability and reliability of HVDC transmission system, expanding the scope of application of HVDC transmission system. With the development of flexible HVDC technology, many people begin to study MTDC [4-6]. For flexible DC transmission system with two ends, if the VSC converter of one end is broken 
and exit operation, then the other end connected with the wind farm will be out of operation[7-9]. But the VSC-MTDC technology can not only solve this problem but also has flexible, reliable and economic characteristics, which is more suitable for distributed generation and power market etc.. So the research of VSC-MTDC technology (such as individual converter coordinated control, wind power through low-voltage technology) has important academic significance and application value.

\section{Basic Operation Principle}

MMC is composed of a plurality of cascaded modules (Sub-Module, SM), these sub modules can be half bridge or full bridge (H bridge) [10,11], the MMC half bridge topology is shown in figure 1 . When the MMC $\mathrm{H}$ bridge is broken in DC lines, it can suppress the fault current, do not need to disconnect the AC breaker, but it uses half bridge switching devices than MMC doubled, the controller is more complex. In two kinds of topologies have advantages and disadvantages, choose according to different needs, the VSC-MTDC system of the converter in my research use the half bridge MMC.

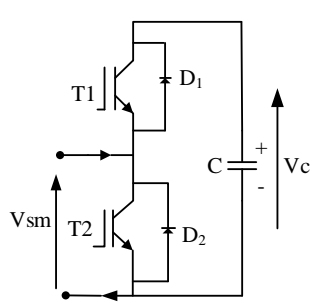

Fig. 1. Half bridge MMC topology

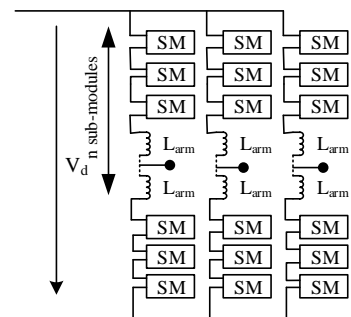

Fig. 2. Three phase MMC topological structure

The MMC topology is shown in Figure 2. It consists of 6 bridge arms, each bridge arm contains a number of structures with the same sub module SM and reactor Larm in series, up and down the two bridge arm to form a phase element. Considering the modular design and construction, the up and down bridge arm of MMC is symmetrical and its three-phase are symmetrical, and the parameters of each sub module are equal to the reactance of each bridge arm. This paper mainly studies the MMC half bridge topology, so the SM module as shown in figure 1.

The difference between MMC and two level VSC topology is there no capacitance on its DC side, its capacitors are distributed in each of the SM sub module. Each sub module SM of MMC is composed of T1, T2 two IGBT, antiparallel combination D1, D2 two diodes and a large capacitor (C). Each SM sub module is the two ends of the component, it can removal (T1 off, T2 open) and input (T1 open, T2 off) in two kinds of current direction switching freely. 
According to the number of the sub modules on the converter bridge arm, the voltage on the converter bridge arm can be adjusted. So a converter bridge arm is a controllable voltage source, which can be controlled by the voltage of the bridge arm to get the output voltage of the converter.

\section{Mathematical Model of VSC-MTDC}

In order to get a more intuitive VSC-MTDC mathematical model based on MMC, this paper takes three terminal VSC- HVDC system which based on the MMC as the research object, its mathematical model is derived, as shown in figure 3. The system is made up with three VSC converters based on MMC topology, and their DC side are connected in parallel. The AC side of the VSC converter are respectively connected with the AC system and have the capability of bidirectional power transmission.

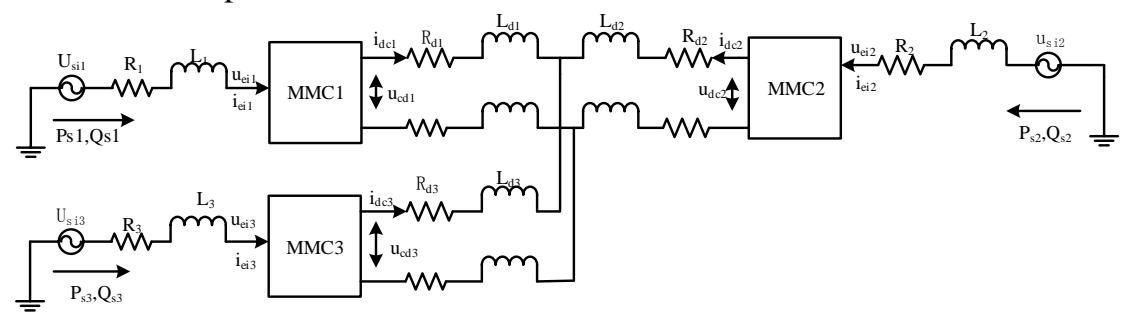

Fig. 3. Three end MMC system structure diagram

According to Kirchhoff's law, the equations of the AC side of converter station three ends of the flexible HVDC system which based on the MMC is

$$
L_{m} \frac{d I_{m}}{d_{t}}=-R_{m} I_{m}+\left(U_{s m}-U_{e m}\right)
$$

The expression of $U_{s m}, I_{m}$ and $U_{e m}$ in the formula is the matrix.

The expression of $L_{m}$ in equation (1) is:

$$
L_{m}=L_{x}+L_{0} / 2
$$

The formula (1) for the dq coordinate transformation can be

$$
\frac{d}{d t}\left[\begin{array}{c}
i_{d m} \\
i_{q m}
\end{array}\right]=\frac{1}{L_{m}}\left[\begin{array}{cc}
-R_{m} & \omega L_{m} \\
-\omega L_{m} & -R_{m}
\end{array}\right]\left[\begin{array}{l}
i_{d m} \\
i_{q m}
\end{array}\right]+\frac{1}{L_{m}}\left[\begin{array}{cc}
u_{s d m} & -u_{e d m} \\
u_{s q m} & -u_{e q m}
\end{array}\right]
$$

$u_{s d m}$ and $u_{s q m}$ are the $\mathrm{m}_{\mathrm{th}}$ VSC AC side of converter station system voltage vector $d$ and $q$ axis component, $u_{e d m}$ and $u_{\text {eqm }}$ are the $\mathrm{m}_{\mathrm{th}}$ VSC converter bridge arm reactor and sub module junction voltage vector $d$ and $q$ axis component, $i_{d m}$ and $i_{q m}$ are the $\mathrm{m}_{\mathrm{th}}$ VSC AC side of converter station system current vector $d$ and $q$ axis component. The last number $\mathrm{m}$ is the representative of the number of 
multiterminal system, there are several HVDC systems, then equation (3) contains several equations.

According to the theory of Park transform and instantaneous reactive power, the active power and reactive power of AC side injected into VSC converter are obtained under the DQ coordinate system:

$$
\left\{\begin{array}{l}
P_{s m}=\frac{3}{2}\left(u_{s d m} i_{d m}+u_{s q m} i_{q m}\right) \\
Q_{s m}=\frac{3}{2}\left(u_{s d m} i_{q m}-u_{s q m} i_{d m}\right)
\end{array}\right.
$$

Assumed three-phase grid voltage balance, set up the AC power grid voltage vector direction is the $\mathrm{d}$ axis direction, $u_{s d}=U_{s}\left(U_{s}\right.$ is the amplitude of voltage of three phase AC system) $u_{s q}=0$, The formula (4) can be simplified as:

$$
\left\{\begin{array}{c}
P_{s m}=\frac{3}{2} u_{s m} i_{d m} \\
Q_{s m}=-\frac{3}{2} u_{s m} i_{q m}
\end{array}\right.
$$

The power of DC side under VSC-MTDC system based on MMC:

$$
P_{d m}=u_{d c m} \cdot i_{d c m}
$$

Without considering the resistance $\mathrm{R}$ and the converter active power loss, the active power which is absorbed from DC side of VSC converter system is equal to the active power from $\mathrm{AC}$ side output, so

$$
\frac{3}{2} U_{s m} i_{d m}=u_{d c m} \cdot i_{d c m}
$$

Formula (3) and (7) is a mathematical model based on the MMC three terminal VSC-HVDC transmission system in the $d q$ coordinate system, It can be extended to the VSC-MTDC system and get other similar mathematical models. According to the mathematical model of the converter, the VSC-MTDC system can be used, but need to be given power distribution station in the outer ring of the DC voltage value and the given value to ensure the balance of power system in DC side.

\section{Voltage Deviation Controller}

DC voltage deviation controller uses a multi-point DC voltage control strategy, but the difference is that the use of DC voltage deviation controller only need to transform the converter station controller, without the need for commutation stations between the communication system can be achieved automatically 
switch control station mode switch. The controller structure is shown in Figure 4, Where $i_{d c r e f 1}, i_{d c r e f 2}$ and $i_{d c r e f 3}$ are the outputs of PI1, PI2 and PI3 respectively.

$$
\text { Its control logic is } i_{d c r e f}=\max \left[i_{d c r e f 1}, \min \left(i_{d c r e f 2}, i_{d c r e f 3}\right)\right]
$$

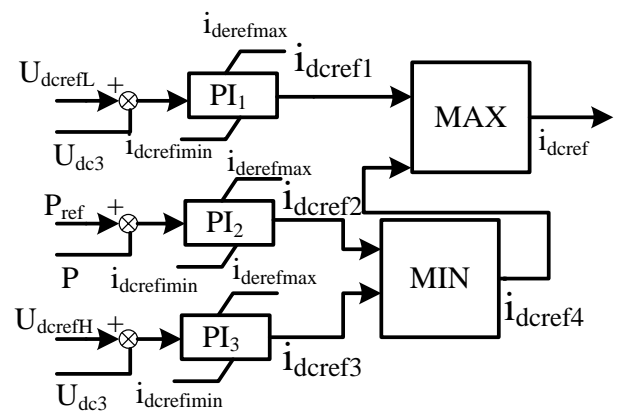

Fig. 4. A power controller based on DC voltage deviation control

In order to ensure the normal operation of the DC voltage deviation controller, the value of $U_{\mathrm{dcrefH}}$ and $U_{\mathrm{dcrefL}}$ should be satisfied:

$$
\left\{\begin{array}{l}
U_{d c r e f L}<U_{d c 3 \min } \\
U_{d c r e f H}<U_{d c 3 \max }
\end{array}\right.
$$

$U_{d c 3 \min }$ and $U_{d c 3 \max }$ are the minimum and maximum values of the steadystate DC voltage at the VSC converter station 3 during normal operation of the VSC converter station 1, respectively. And $U_{d c 3}$ satisfies the following relation when VSC converter station 1 is in normal operation:

$$
U_{d c r e f L}<U_{d c 3}<U_{d c r e f H}
$$

Due to the role of PI controller, so in the VSC converter station 1 normal operation, there are:

$$
\left\{\begin{array}{l}
i_{d c r e f 1}=i_{d c r e f \min }<i_{d c r e f 2} \\
i_{d c r e f 3}=i_{d c r e f \max }>i_{d c r e f 2}
\end{array}\right.
$$

By the formula (11) can be obtained, the output of the DC voltage deviation controller $i_{\text {dcref }}$ is determined by the $i_{\text {dcref } 2}$. That is to say, the output of the DC voltage deviation controller is determined by the fixed active power controller conclusions. 


\section{Conclusions}

The multi-terminal DC transmission system based on MMC is studied in this paper, depth research on the related technologies and problems, and has made the following conclusions:

(1) The basic principle of MMC is analyzed, and the mathematical model of VSC-MTDC based on MMC is established in the synchronous rotating $d q$ coordinate system, and the active component and reactive power component are decoupled. Compared with the DC transmission system at both ends, although the multi-terminal system model in the $d q$ coordinate system is more complex, it will affect the power coordination control among the multiple converter stations, but has no effect on the station-level basic control of the VSC converter station.

(2) The DC voltage slope control of the multi-terminal system is studied. The DC voltage slope controller compensates for the limitation of using only one converter station as the DC voltage control station.

\section{References}

1. Chen Xia, Sun Haishun, Yuan Xu feng, et a1. Integrating wind farm to the grid using hybrid multi-terminal HVDC technology [C] //IEEE Industrial and Commercial Power Systems Technical Conference. Aiken: IEEE, 2010: $1-6$.

2. Zhijie Liu, Ke-Jun Li, Xinhan Meng, et a1.Dynamic simulator for multiterminal direct current transmission system [C]// Industry Applications Society Annual Meeting, 2016 IEEE, 2016:2-6.

3. G.Asplund, K. Eriksson, K. Svensson. DC Transmission Based on Voltage Source Converters [C]. GIGRE SC14 Colloquium, South Africa, 1997:1-8.

4. Wei Xiaoguang, Tang Guangfu, Wei Xiaoyun, et al. Study on the voltage fluctuation of the wind farm with VSC-HVDC controller [J]. Journal of electrical engineering, 2007, 22 (4): 150-157.

5. Biyang Wang, Xifan Wang, Xiuli Wang, et a1.Reliability evaluation of voltage-source converter-based multi-terminal direct current integrated offshore wind plants [J]// Renewable Power Generation. Glasgow: IET, 2016, 10 (6): 761-766.

6. Li Wenjin, Tang Guang Fu, he Zhiyuan DFIG wind farm. The modular flexible DC grid control strategy [J]. automation of electric power system of multilevel, 2013, 37 (15): 20-26.

7. Xu L, Yao L, Bazargan M. DC grid management of a multi-terminal HVDC transmission system for large offshore wind farms[C]. Proceedings of First SUPERRGEN Conference. Nanjing, China: Electric Power Automation Equipment, 2009:20-25.

8. WANG Wenyuan, BAMES M. Power flow algorithms for multiterminal VSC-HVDC with droop control[J]. IEEE Trans on Power Systems,2014,29(4) : 1721-1730. 
9. ZHENG Xiaodong, TAI Nengling, WU Zhongyu, et al. Harmonic current protection scheme for voltage source converter-based highvoltage direct current transmission system [J]. IET Generation, Transmission \& Distribution, 2014, 8(9): 1509-1515.

10. Dorn J., Huang H., Retzmann D. A new Multilevel Voltage-Sourced Converter Topology for HVDC Applications, Cigré Session, B4-304, 2008, Paris.

11. R. Marquardt, "Modular Multilevel Converter topologies with DC-Short circuit currentlimitation," IEEE 8th International Conference on Power Electronics and ECCE Asia (ICPE\&ECCE), 2011, pp.1425-1431. 